Research Article

\title{
Investigation of Engineering Properties of Cement-Stabilized Calcareous Sand Foundation
}

\author{
Yuan Chai $\mathbb{D}^{1},{ }^{1}$ Dai-Ping Jiang, ${ }^{2}$ Fu-Jiang Wang, ${ }^{2}$ and Hai-Bo Lyu $\mathbb{D}^{2,3}$ \\ ${ }^{1}$ College of Civil Engineering and Architecture, Guangxi University, Nanning530000, China \\ ${ }^{2}$ College of Civil Engineering and Architecture, Guilin University of Technology, Guilin 541000, China \\ ${ }^{3}$ Collage of Architecture and Electrical Engineering, Hezhou University, Hezhou 542800, China
}

Correspondence should be addressed to Hai-Bo Lyu; lhb@glut.edu.cn

Received 13 September 2021; Revised 4 November 2021; Accepted 12 November 2021; Published 3 December 2021

Academic Editor: Ivan Giorgio

Copyright (C) 2021 Yuan Chai et al. This is an open access article distributed under the Creative Commons Attribution License, which permits unrestricted use, distribution, and reproduction in any medium, provided the original work is properly cited.

Calcareous sand is widespread around Nansha Islands, South China Sea. In oceanic and coastal engineering, calcareous sand is usually used as a building foundation and backfill material for airport runway embankments. The engineering characteristics of calcareous sand is different from terrigenous sand because of its irregular grain shape, lower particle strength, and internal voids, which have caused many engineering problems in the last decades. Cement-stabilized soil, as a common foundation reinforcement method, can solve these engineering problems and improve the foundation strength effectively. Therefore, it is very important to estimate the engineering characteristics of cement-stabilized calcareous sand foundations. In this paper, the basic engineering characteristics, bearing capacity, and deformational behavior of calcareous sand were studied by carrying out a series of tests on cement-stabilized calcareous sand. It is found that: (1) the uniaxial compression strength of calcareous sand is higher than that of Guangzhou soft soil but lower than that of filter medium quartz sand; (2) the deformation of the calcareous sand under compression is mainly plastic, and the elastic deformation gradually increases with increasing cement content; (3) the apparent cohesion of calcareous sand increases, while internal friction angle decreases with increasing cement content; (4) cement-stabilized method can significantly improve the bearing capacity of calcareous sand foundation, especially for the saturated state. A cement content equal to or more than $15 \%$ and a thickness of $1 / 8$ of the foundation can effectively improve the bearing capacity of the foundation; and (5) the ultimate bearing capacity of the foundation by numerical calculation is higher than that by experiments, while the settlement by calculating is lower.

\section{Introduction}

Calcareous sand, which consists of skeletal remains of marine organisms, is mainly distributed on the surroundings of islands and seashores throughout the world, such as the South China Sea, Red Sea, and waters of Western Australia [1]. Because the calcareous sands consist of shells fragments and corals debris, the shape of calcareous sand particles are quite irregular, and the particles could be easily crushed [2]. As a result, their geotechnical properties are quite different from those of quartz sand and other terrigenous soils. In oceanic and coastal engineering projects, calcareous sand was used as foundation and backfill materials for road embankments or airport runways. The traditional techniques such as pile driving and foundation treatment, which are successful for terrigenous soils, have been proved to be ineffective when applied to calcareous sand $[3,4]$.

The special properties of calcareous sands have caused many engineering problems in the last decades. The first engineering problem occurred in the 1960s when the ESSO Australia designed the pile system of the construction of a project in calcareous sands near the Bass Strait that pile driving was easier than expected during production platform installation [5]. In the early nineteenth century, a series of tests on half-a-meter-long steel pipe were tackled to check and assess the situation. The reason is the uneven settlement of the foundation caused by the high crushability and low shear resistance of calcareous sediments [6]. In the tropical and subtropical regions around the Pacific Ocean, calcareous sand is distributed in shallow water and near the coast, such 
as Guam, Hawaii, Haiti, and some other places. In these areas, without proper foundation treatment, calcareous sand was observed to be liquefied and lost stability by seismic hazards, posing a threat to the offshore structures, wharves, and ports [7]. Besides, many engineering accidents of marine construction have been caused by the special mechanical properties of calcareous sand [8].

Recently, the mechanical properties of calcareous sand, such as fall velocity, critical shear stress, drag coefficient, and transport rate, have been extensively studied [9-11]. The engineering behavior of calcareous sands was evaluated by the bearing capacity and settlement of slide-resistant piles [12-15]. Wang [16] conducted a drawing test of driven steel pile in the lightly cemented calcareous sand foundation in the Gulf of Suez and proposed that the formation process, degree of cementation, and particle breakage of calcareous sands were the main factors affecting the bearing characteristics of the foundation. Hyodo et al. performed a series of large strain ring shear tests on calcareous sands of Dogs Bay and found that particle breakage happened at low stress $(0.8 \mathrm{MPa} \sim 1.0 \mathrm{MPa})$ [17]. Shaqour used a miniature penetrometer to study the bearing capacity of cemented calcareous sand ground under changing groundwater flowing levels and claimed that the strength of cemented calcareous reduced significantly when immersed in water [18]. The bearing capacity and deformation behavior of calcareous sand on the Yongshu Reef, South China Sea, were investigated by the corresponding laboratory plate load tests, and it was found that calcareous sand ground is much stiffer than quartz sand ground [19-21]. The extremely irregular shape of calcareous sands will make their particles form occlusal embedded structures after compaction, and the bearing capacity can be improved by engineering methods such as rolling and tamping, which is generally applicable to construct buildings or roads [4, 22]. However, for high-rise buildings or airport runways and other structures, simple compaction treatment cannot meet the engineering requirements. Cement-stabilized soil, as a common foundation reinforcement method, can improve the foundation strength effectively.

Because of low cost, quick construction speed, and simple reinforcing forms, cement-stabilized soil is widely used [23]. The cemented mechanism, chemical compositions, internal pore structure, and properties of the cemented-stabilized soil were studied by X-ray diffraction (XRD), mercury intrusion porosimeter test (MIP), scanning electron microscope (SEM), acoustic emission technology, and computed tomography scans (CT) [24, 25]. Some research also compares the properties of cement-stabilized soil with or without fiber reinforcement and attempted to add different kinds of reinforcers such as corn silk fibers and tire rubber fibers [26, 27]. The cement-stabilized method has been mainly applied in clay, silt, or soft clay soil. The study on the cement solidification method for calcareous sand is limited.

In this study, Portland cement was used for stabilizing calcareous sand. A series of uniaxial compression tests, shear tests, oedometer tests, and laboratory plate load tests (PLT) were performed on calcareous sand samples with different cement contents. The shear strength, compression property, compression strength, and bearing capacity of the cementstabilized calcareous sand were investigated. The ultimate bearing capacity and the settlement of calcareous sand foundation calculated by the specifications method were compared to the experimental results. The test results and viewpoints can provide scientific references for oceanic and coastal engineering.

\section{Materials and Methods}

\subsection{Test Materials}

2.1.1. Calcareous Sand. The calcareous sand used in this study was obtained from Luhuitou Fringing Reef in the South China Sea. Luhuitou Fringing Reef is a leeward and low wave coast at the west coast of Sanya City, the southern tip of Hainan Island, China [28]. This area belongs to the same sea area as Yongshu reef and Meisha reef in the South China Sea that consists of quantities of reef limestone and calcareous sands. The calcareous sand in both places is similar in mineralogy. Figure 1 shows the calcareous sand used in this study, and it is obvious that its particle shape is quite irregular.

In order to ensure the cementing effect, the particle size greater than $2 \mathrm{~mm}$ is removed because of the small sample size in some tests. Figure 2 shows that the particle size distribution (PSD) of calcareous sand. It is of medium sand with little fines as a direct result of scouring by offshore sea currents. The initial water content of calcareous sands is $10 \%$ $( \pm 0.4 \%)$, and the physical properties of calcareous sand from the South China sea and other places are shown in Table 1. The gravity of calcareous sands in this study is lower than the others due to the relatively lower content of $\mathrm{CaCO}_{3}$. The $e_{\max }$ of the calcareous sands in this study is higher while the $e_{\min }$ is lower than the calcareous in the literature. In a loose state, the space between particles is big, thus a larger void ratio. On the other hand, the space between calcareous sand particles can be reduced by compaction to obtain a higher relative density.

2.1.2. Portland Cement. The Portland cement used was type PO 42.5, and the chemical compositions of the cement by percentage were listed in Table 2. The basic properties of the Portland cement are summarized in Table 3.

2.2. Test Preparation. The cement percentages for cementstabilized soil foundation generally ranged from $5 \%$ to $25 \%$ by soil weight [29]. The cement percentage of cemented calcareous sand should be controlled within a certain range to consider the increase of self-weight stress of composite foundation caused by reinforcement materials; furthermore, the self-weight should be as small as possible based on maintaining soil strength. Yao, et al. conducted a series of tests to investigate the engineering characteristics of the cemented soil admixed with 5\% 18\% cement content. Thus, $5 \%, 10 \%$, and $15 \%$ of cement incorporation are adopted in this paper. 


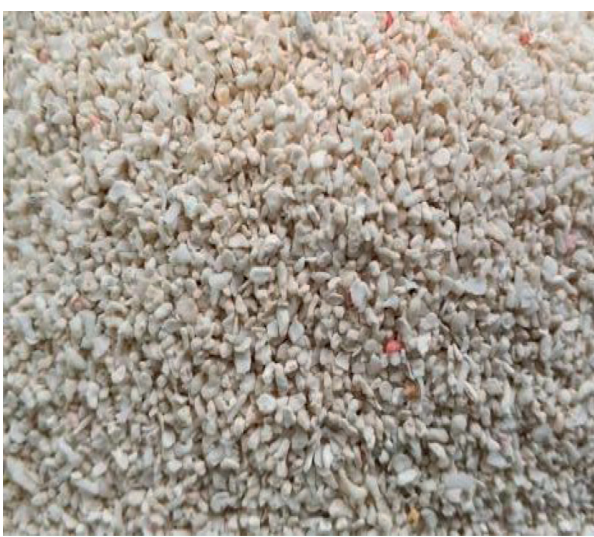

(a)

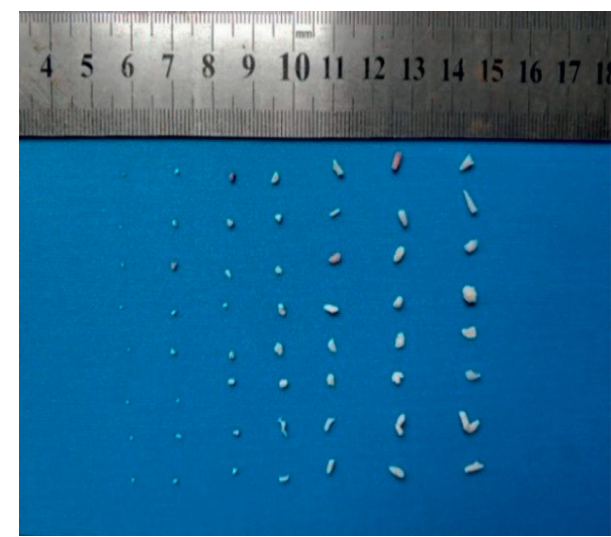

(b)

Figure 1: Specimens of calcareous sands.

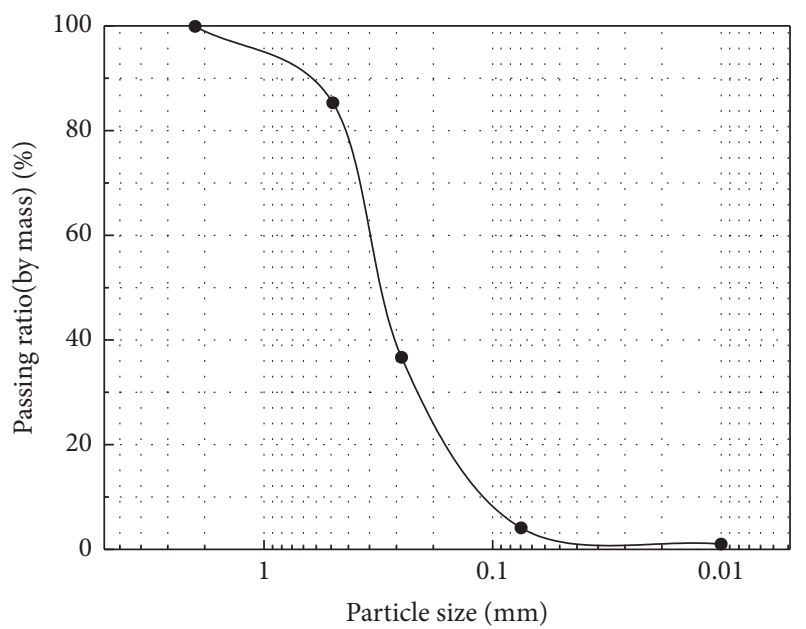

Figure 2: Particle size distribution of calcareous sand.

TABle 1: Overview of sand characteristics $[28,29]$.

\begin{tabular}{lccccc}
\hline Sand & $G_{s}(-)$ & $D_{50}(\mathrm{~mm})$ & $\mathrm{CaCO}_{3}(\%)$ & $e_{\max }(-)$ & $e_{\min }(-)$ \\
\hline This study & 2.73 & 0.36 & 89 & 1.510 & 0.801 \\
S1 & 2.84 & 0.59 & 95 & 1.278 & 0.741 \\
BAE & 2.84 & 0.27 & 93 & 1.511 & 0.979 \\
BAW & 2.84 & 0.57 & 98 & 1.392 & 0.843 \\
Dogs Bay & 2.75 & 0.24 & $87 \sim 92$ & 1.830 & 0.980 \\
Quiou & 2.72 & 0.71 & 77 & 1.281 & 0.831 \\
Kenya sand & 2.79 & 0.13 & 97 & 1.776 & 1.282 \\
Cabo Rojo & 2.86 & 0.38 & 93 & 1.710 & 1.340 \\
\hline
\end{tabular}

\subsection{Test Methods}

2.3.1. UCS Test, Direct Shear Test, and Oedometer Test. UCS tests were performed following the Chinese standard GB/T 50123-2019. The specimen is a cylinder with a diameter of $3.18 \mathrm{~cm}$ and a height of $5.00 \mathrm{~cm}$. Before the test, the mixed sand and cement were filled in the sample preparation mold in three equal layers and compacted with a jack. The dry density of samples was controlled as $1.42 \mathrm{~g} / \mathrm{cm}^{3}$. Then the specimens were wrapped with preservative film and submerged in water for curing.
Standard direct shear tests were performed in the laboratory by the strain-controlled direct shear apparatus. This apparatus consisted of four soil sample boxes are used to measure the shear strength of sands under different vertical pressure. The cemented sand sample was a cylinder with the size of $30 \mathrm{~cm}^{2} \times 2 \mathrm{~cm}$. All the calcareous sand samples were mixed with cement and compacted in the cylinder mold by immersion in water. After $72 \mathrm{~h}$, the cemented samples were removed from the molds, wrapped in vinyl bags, and stored in a humidity chamber. The vertical stress (four tests) was set as $100 \mathrm{kPa}, 200 \mathrm{kPa}, 300 \mathrm{kPa}$, and $400 \mathrm{kPa}$. A shearing rate of $0.02 \mathrm{~mm} / \mathrm{min}$ was used, and the shear test was stopped until the occurrence of the greatest shear stress or $6 \mathrm{~mm}$ displacement, whichever occurs earlier.

For oedometer tests, the size of the samples was as same as those of direct shear tests, and every specimen underwent the process: load-unload-load. The consolidation pressure was ordered by $50 \mathrm{kPa}, 100 \mathrm{kPa}, 200 \mathrm{kPa}, 400 \mathrm{kPa}, 800 \mathrm{kPa}$, $400 \mathrm{kPa}, 200 \mathrm{kPa}, \quad 100 \mathrm{kPa}, 200 \mathrm{kPa}, 400 \mathrm{kPa}, \quad 800 \mathrm{kPa}$, $1,600 \mathrm{kPa}$, and $3,200 \mathrm{kPa}$.

2.3.2. Laboratory Plate Load Test. In order to investigate the bearing capacity and deformation behavior of cement-stabilized calcareous sand, a series of laboratory plate load tests were conducted in a model test steel bucket. The diameter and the height of the steel bucket were both $0.8 \mathrm{~m}$. A square plate, made of $15 \mathrm{~mm}$ thick steel, was specially designed as the bearing plate. The size of the bearing plate of the laboratory plate load test in standard is not clear, but a bearing plate with a larger size avoiding boundary effect can improve the accuracy of the results. Wang proposed that the distance between the bearing plate and the model box should be kept at least 2 2.5 times the width of the bearing plate [19]. Hence, the size of the bearing plate in this test was set as $130 \mathrm{~mm} \times 130 \mathrm{~mm}$.

The load was applied through the universal testing apparatus that could measure the displacement at the same time. Five soil pressure cells are installed in the calcareous sands of the steel bucket to measure additional stress caused by the bearing plate, and soil pressure cells are installed only 
TABle 2: Chemical composition of Portland cement PO 42.5.

\begin{tabular}{lccccccccc}
\hline Component & $\mathrm{CaO}$ & $\mathrm{SiO}_{2}$ & $\mathrm{Al}_{2} \mathrm{O}_{3}$ & $\mathrm{Fe}_{2} \mathrm{O}_{3}$ & $\mathrm{MgO}$ & $\mathrm{N}_{2} \mathrm{O}$ & $\mathrm{SO}_{3}$ & $\mathrm{~K}_{2} \mathrm{O}$ & $\mathrm{Loss}$ \\
\hline Content (in mass) \% & 63.47 & 24.56 & 5.31 & 3.03 & 1.16 & 0.93 & 0.89 & 0.65 & 0 \\
\hline
\end{tabular}

Table 3: Properties of Portland cement PO 42.5.

\begin{tabular}{|c|c|c|c|c|c|c|}
\hline \multirow[t]{2}{*}{ Cement grade } & \multicolumn{2}{|c|}{ Setting time } & \multicolumn{2}{|c|}{$\begin{array}{l}\text { Compressive strength } \\
(\mathrm{MPa})\end{array}$} & \multicolumn{2}{|c|}{$\begin{array}{l}\text { Flexural strength } \\
(\mathrm{MPa})\end{array}$} \\
\hline & Initial & Final & $3 \mathrm{~d}$ & $28 \mathrm{~d}$ & $3 \mathrm{~d}$ & $28 \mathrm{~d}$ \\
\hline PO 42.5 & 189 & 276 & 25.7 & 49.1 & 4.4 & 8.6 \\
\hline
\end{tabular}

on the half side of the model test bucket according to the principle of symmetry. Since the distribution of additional stress generated by foundation load is parabolic, two soil pressure cells were installed in the upper and lower positions of the model test bucket, and the three other soil pressure cells were installed in the middle part of the model test bucket. The soil pressure cells should be kept at a distance from the model box wall and could not be installed close to the model test bucket wall. Figure 3 presents the diagram of the plate load test system and the layout of soil pressure cells.

When filling sands into the model test steel bucket, the calcareous sand was compacted every $100 \mathrm{~mm}$ by using the undercompaction concept [31]. It was advantaged for specimen obtaining almost the same density throughout all specimens consistently. The relative density of calcareous sand in this test was $56 \%$.

Two different thicknesses of the cemented sand layers $(5 \mathrm{~cm}$ and $10 \mathrm{~cm})$ were tested. The cemented layer was the mixture prepared with cement, calcareous sand, and water according to designated proportions. The cemented calcareous sands were mixed in advance before the test, and the water-cement ratio was controlled at 0.5 . In the same way, the cemented calcareous sands were filled into the model bucket to cover the foundation and compacted every $100 \mathrm{~mm}$, and the thickness of the cement layer was strictly controlled.

As summarized in Table 4, the factors including cement content, water content, and layer thickness of cement-stabilized calcareous sand were studied. Seven tests were conducted according to the testing programme, and the test was carried out following the ASTM standard D1194-94.

\section{Results and Discussion}

3.1. UCS. Figure 4 shows the stress-strain curves of cemented calcareous sand with cement contents of $5 \%, 10 \%$, and $15 \%$ at different curing times. Their failure process is similar, which could be divided into three stages, that is, an elastic stage, a softening stage, and a failure stage. During the elastic stage, the stress increases linearly with axial strain, and the higher the cement content, the stiffer the slope is. However, in the softening stage, the increasing rate of stress slows down obviously, indicating more plastic deformation occurs as the axial strain increases. The peak stress appears at this stage, followed by the specimen's destruction and a sharp drop in the stress.

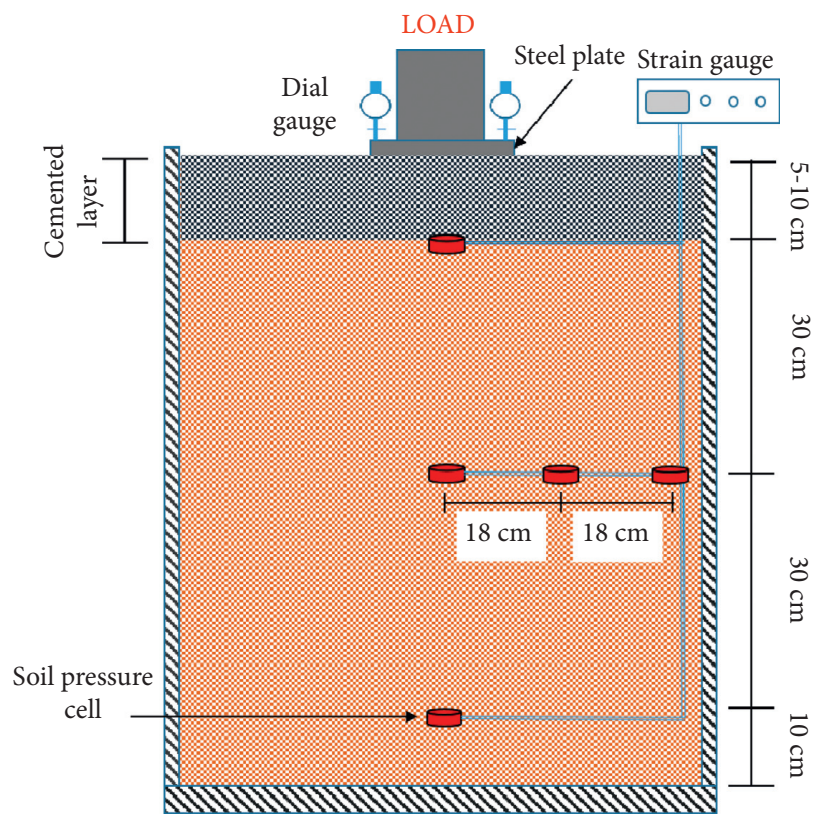

Figure 3: Diagram of the plate load test.

The peak strength of UCS of cemented calcareous sand and cemented soils from literature are summarized in Table 5. For the specimens with the same cement content, the peak strength of cemented calcareous sand is much higher than that of Guangzhou soft soil but lower than the filter medium sand. The filter medium sand is quartz sand, whose particle strength is relatively higher than that of calcareous sand [34]; thus, the UCS of filter medium sand is higher than that of calcareous sand. This result similarly agrees with Da's conclusion, that is, the compressive strength of coral sand concrete is lower than that of quartz sand concrete with the same mix proportion [35]. Therefore, it can be seen that the UCS of cemented calcareous sand is higher than that of some soils but not as high as that of cemented quartz sand.

Figure 5 shows the influence of curing time on the UCS of cemented calcareous sand with different cement content. When the curing time is less than $7 \mathrm{~d}$, the UCS of the specimen with different cement content increases obviously; however, when the curing time is more than $7 \mathrm{~d}$, the growth rate of UCS growth slows down By contrast, previous studies showed that when the soil foundation was cement-stabilized, this time node generally appeared after $14 \mathrm{~d}$ or $21 \mathrm{~d}$, so the cemented calcareous sand hardened faster than cemented 
TABLE 4: Experiment scheme of PLTs.

\begin{tabular}{lcccc}
\hline Test group number & Water content & Cemented layer thickness & Cement incorporation ratio & Curing time \\
\hline 1 & Dry & - & - & - \\
2 & Saturated & - & $5 \%$ & - \\
3 & Dry & $10 \mathrm{~cm}$ & $10 \%$ & $3 \mathrm{~d}$ \\
4 & Dry & $10 \mathrm{~cm}$ & $15 \%$ & $3 \mathrm{~d}$ \\
5 & Dry & $10 \mathrm{~cm}$ & $10 \%$ & $3 \mathrm{~d}$ \\
6 & Dry & $5 \mathrm{~cm}$ & $10 \%$ & $3 \mathrm{~d}$ \\
7
\end{tabular}

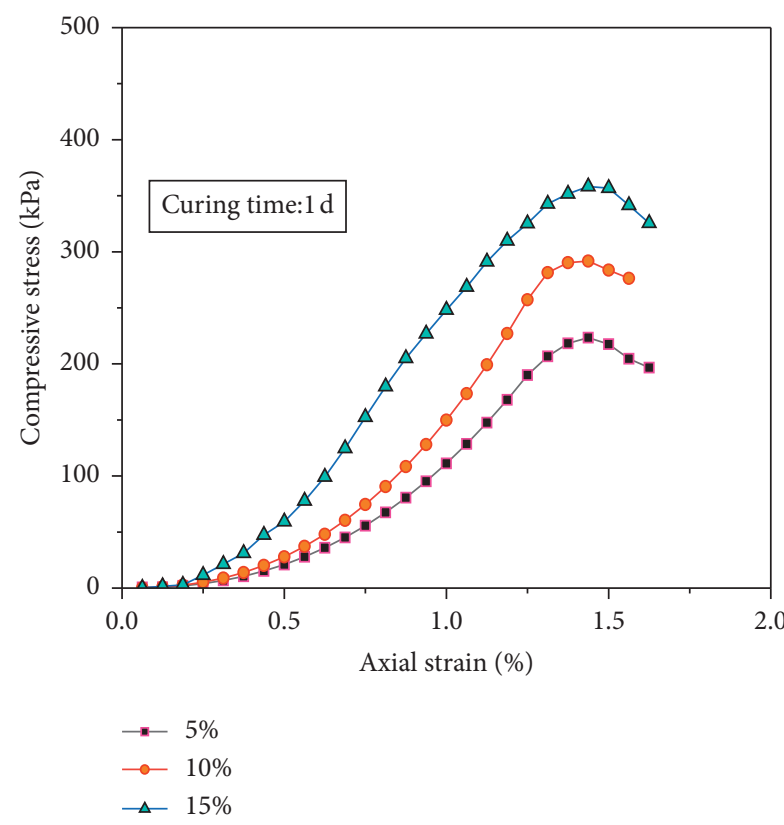

(a)

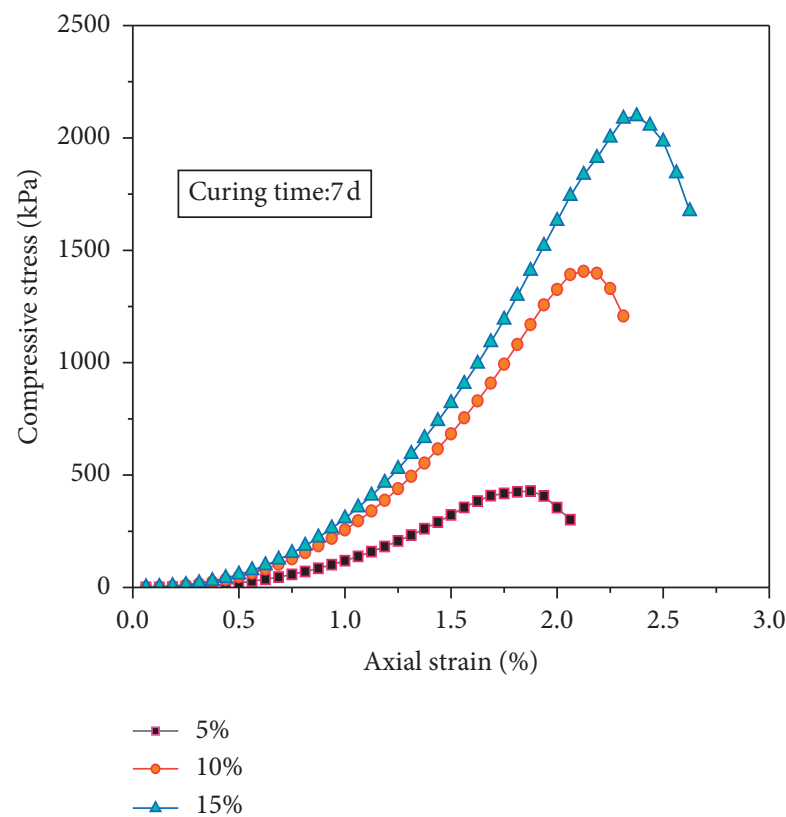

(c)

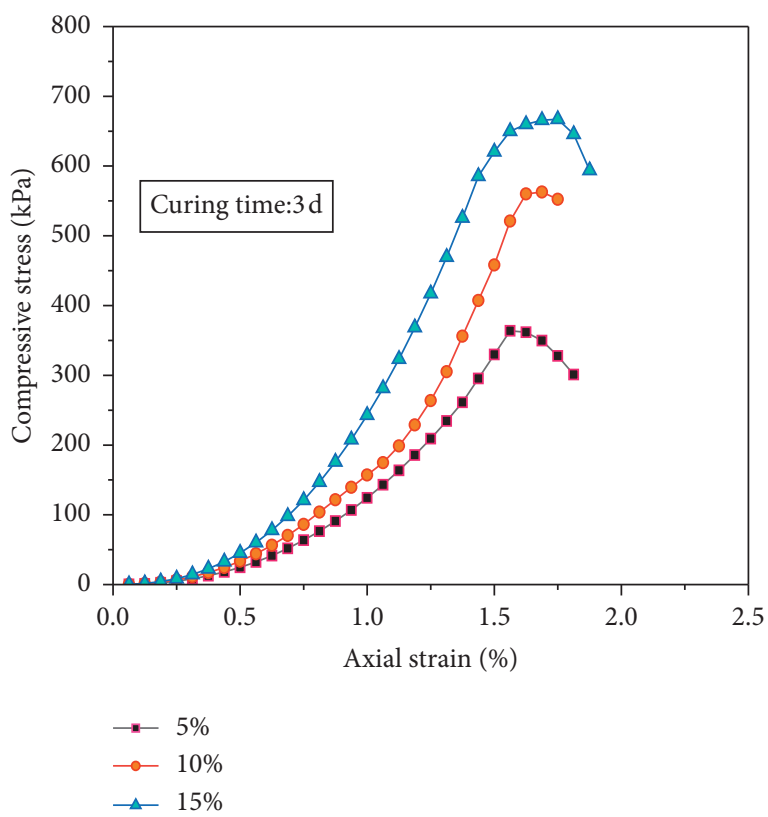

(b)

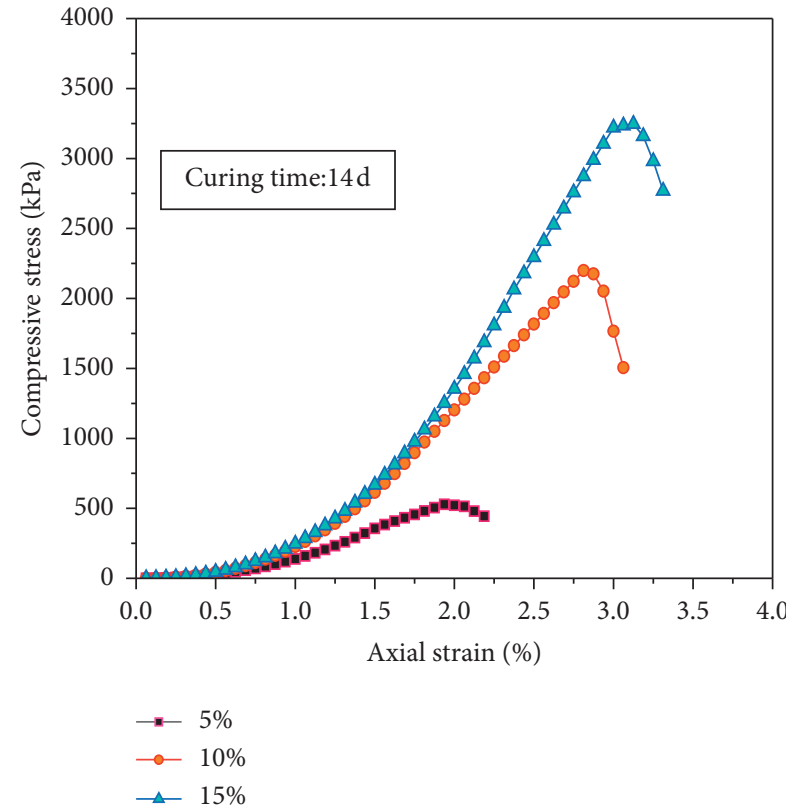

(d)

FIGURE 4: Stress-strain curves for UCS test results. 
TABLE 5: The peak strength of UCS tests.

\begin{tabular}{lccc}
\hline \multirow{2}{*}{ Materials } & \multirow{2}{*}{ Cement content (\%) } & \multicolumn{2}{c}{ UCS $(\mathrm{kPa})$} \\
& $5 \mathrm{~d}$ & $14 \mathrm{~d}$ \\
\hline \multirow{2}{*}{ Calcareous sand } & 10 & 368.9 & 528.8 \\
& 15 & $1,406.3$ & $2,199.2$ \\
Guangzhou soft soil [32] & 10 & $2,185.4$ & $3,273.2$ \\
& 15 & 489.5 & 238.4 \\
Filter medium sand [33] & 5 & 411.7 & 652.2 \\
& 10 & $2,449.7$ & $3,089.4$ \\
\hline
\end{tabular}

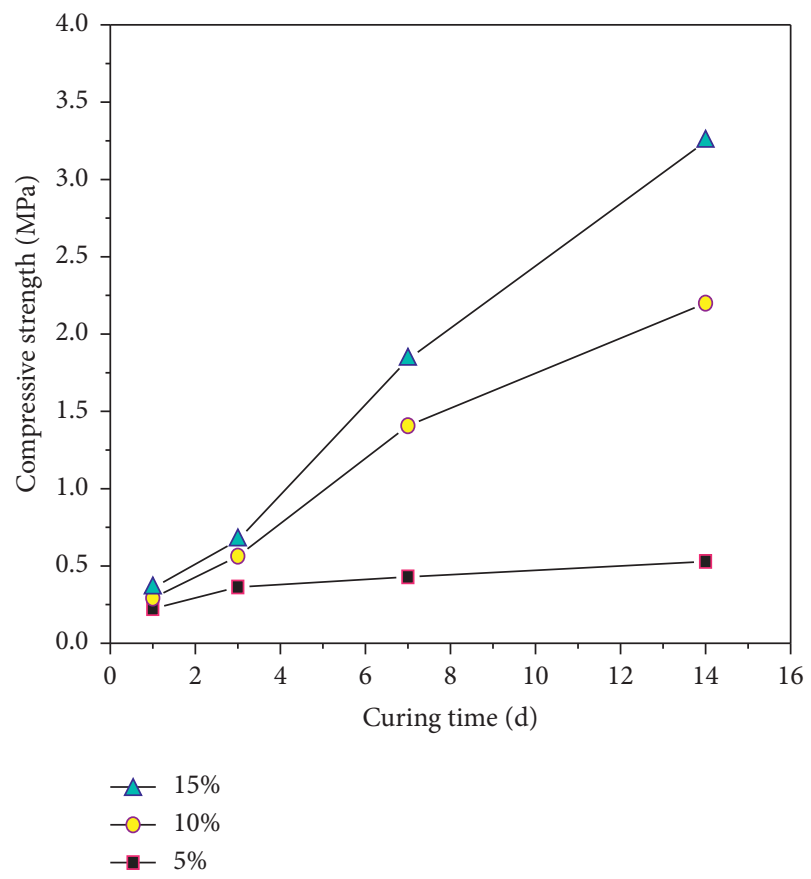

FIGURE 5: Influence of curing time on the UCS with different cement content.

clay or cemented quartz. This may be due to the higher water absorption of calcareous sand caused by its porous structure. When cement is hardening, the absorbed water in the pore is discharged to participate in the hydration reaction thus increasing the cement hydration rate.

In addition, the growth trend of compressive strength of specimens with different cement contents is not entirely consistent. The compressive strength of specimens with $10 \%$ and $15 \%$ content of cement increased obviously faster compared to specimens with $5 \%$ cement content. The stacked crystals generated by cement hydration connect the particles to enhance the strength of samples. If only a little cement is added, few crystals are produced so that it is difficult to connect all particles inside the material resulting in low strength. The compressive strength of specimens with 5\%,10\%, and $15 \%$ content of cement for $14 \mathrm{~d}$ increased by $698 \%, 596 \%$, and $129 \%$, respectively (compared to the specimens cured for 1 day).

3.2. Direct Shear Test Results. Figure 6 shows the Coulomb shear strength envelops of calcareous sand with different cement contents. The apparent cohesion and internal friction angles of the samples by direct shear tests are summarized in Table 6. The apparent cohesion of $5 \%$ cemented calcareous sand increased by $2.51 \mathrm{kPa}$ than that of uncemented calcareous sand, and the internal friction angles decreased from $36.50^{\circ}$ to $34.07^{\circ}$, a decrease of $6.7 \%$. When the cement content increased to $10 \%$ and $15 \%$, the apparent cohesion of cemented calcareous sand compared to that of uncemented drastically increased by $20.58 \mathrm{kPa}$ and $30.25 \mathrm{kPa}$, respectively. The internal friction angles decreased by $9.0 \%$ and $9.4 \%$, respectively.

The internal friction angle tested here was a little lower than the average. This is due to the small particle size in the test, which leads to a low bite force between particles, resulting in smaller friction. In addition, the special sample preparation method causes a high water content of samples after curing in the water, and thus, this also decreases the friction.

The apparent cohesion of calcareous sand increases with cement content, while the internal friction angle decreases with the cement content. The increase of apparent cohesion is induced by the increase of cohesion between calcareous sand particles after cementing. For the internal friction angle, the corners of calcareous sand particles are usually sharp, so the internal friction angle is large. The peak value of the internal friction angle of calcareous sand obtained by Brande is $34.6^{\circ} \sim 35.7^{\circ}$ (however, the internal friction angle of standard quartz sand is about $28^{\circ} \sim 29^{\circ}$ ) [34]. When the cement adhesive gel is attached to the particles, the holes on the surface of the particles are filled, and the edges are wrapped in cement, thus no longer sharp. Therefore, compared to the uncemented calcareous sand, the cemented calcareous sand particles easily slide over each other under shearing, the internal friction angle decreases as a result.

3.3. Oedometer Test Results. Figure 7 shows the $e-P$ relationships of cemented calcareous sand by oedometer test. The compression behavior of cemented calcareous sands with different cement content is similar. Compared with uncemented calcareous sand, the compression modulus of cemented calcareous sands is higher. For cemented calcareous sand, there is gelation between particles, so the void ratio of the compression curve does not change much at the beginning, and only a few particles are repositioned under pressure.

From the unload-reload parts of the curves, the rebound of plain calcareous sand is smaller than that of the cemented calcareous sand. It indicates that the deformation of calcareous sand in the process of compression is mainly irreversible plastic. When the calcareous sand is cemented, the rebound of consolidated sand increases obviously with the increase of cement content. Due to the presence of cementation, a partial plastic strain is converted into elastic strain, and the elastic deformation is about $6.1 \% \sim 32.3 \%$ of the total deformation.

In the classical theory of soil mechanics, some indices are commonly used to describe the compression characteristics of soil (e.g., consolidation yield stress, $P_{y}$; compression in$\operatorname{dex}, C_{c}$; swelling index, $C_{s}$; and compression modulus $E_{s}$ ). 


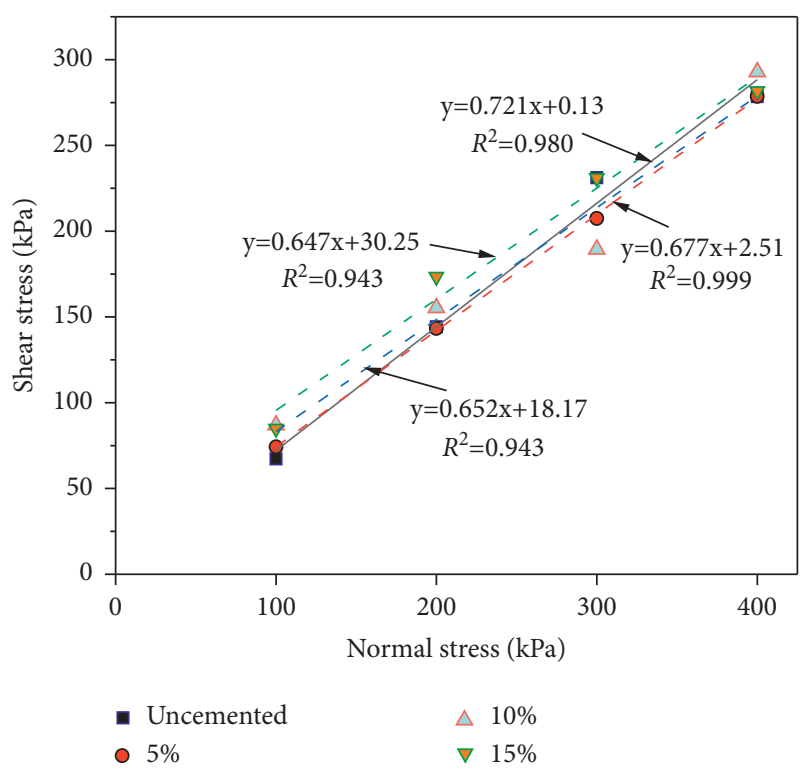

FIGURE 6: Coulomb shear strength envelops of calcareous sand with and without cement.

TABLE 6: Shear strength indices of different types of calcareous sands.

\begin{tabular}{lccc}
\hline $\begin{array}{l}\text { Cement content } \\
(\%)\end{array}$ & $\begin{array}{c}\text { Apparent } \\
\text { cohesion, } c(\mathrm{kPa})\end{array}$ & $\begin{array}{c}\text { Internal friction } \\
\text { angle, } \varphi\left({ }^{\circ}\right)\end{array}$ & $R^{2}$ \\
\hline Uncemented & 0 & 36.50 & 0.9706 \\
5 & 2.51 & 34.07 & 0.9975 \\
10 & 18.17 & 33.20 & 0.9928 \\
15 & 30.25 & 33.07 & 0.9653 \\
\hline
\end{tabular}

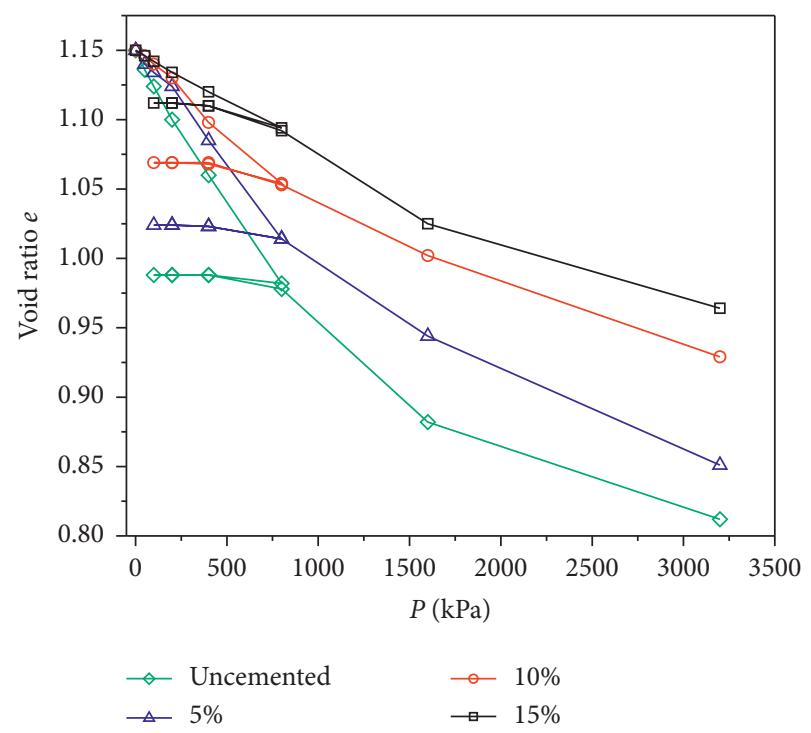

FIGURE 7: Oedometer curves of calcareous sand with and without cement.

Among these indices, the consolidation yield stress is usually obtained by the single logarithmic coordinate method (Casagrande, 1936) or the bilogarithmic coordinates method (Butterfield, 1979) [36, 37]. When the data points are few, the consolidation yield stress determined by Casagrande's method is easy to be distorted, while Butterfield's method using the intersection of two fitting lines as the consolidation yield stress can better solve this problem. According to Butterfield's method, the coordinate axes are converted into bilogarithmic coordinate axes, $\ln (1+e)-\ln P$, and the data in the unloading process are eliminated to avoid affecting the fitting results. The consolidation yield stress is shown in Figure 8, and after the data process, the compression curve of cemented calcareous sand is composed of two straight lines bounded by a yield point. Before the yield point, the compression curve is gentle, while it becomes steep after the yield point. By means of each intersection point, the consolidation yield stress of uncemented specimen and cemented specimen with cement contents of $0 \%, 5 \%, 10 \%$, and $15 \%$ is $396 \mathrm{kPa}$, $450 \mathrm{kPa}, 500 \mathrm{kPa}$, and $633 \mathrm{kPa}$, respectively.

The other indexes are calculated by the following equations, respectively:

$$
\begin{aligned}
& E_{s}=\frac{P_{2}-P_{1}}{e_{1}-e_{2}}\left(1+e_{1}\right), \\
& C_{c}=\frac{e_{1}-e_{2}}{\lg P_{2}-\lg P_{1}}, \\
& C_{s}=\frac{e_{1}^{\prime}-e_{2}^{\prime}}{\lg P_{2}^{\prime}-\lg P_{1}^{\prime}},
\end{aligned}
$$

where $e_{1}$ and $e_{2}$ are void ratios corresponding to consolidation stresses of $P_{1}$ and $P_{2}$ in the loading phase, respectively, and $e^{\prime} 1, e^{\prime} 2, P^{\prime} 1$, and $P^{\prime} 2$ have the same meaning of the unloading phase.

The maximum value of these indices was selected to describe the test results. Table 7 listed the values of compression modulus $\left(E_{s}\right)$, swelling index $\left(C_{s}\right)$, and compression index $\left(C_{c}\right)$ of calcareous sand and other five different soils.

Carer tested calcareous sand obtained from the northwest coast of Australia, where $C_{c}=0.18 \sim 0.24, C_{s}=0.065$, and $C_{c} / C_{s}=12.62$. As can be seen from Table 6, the compression indices of calcareous sand in this study are not much different from those of Carer. When the content of cement increases, $C_{\mathrm{c}} / C_{\mathrm{s}}$ of cemented calcareous sand is close to that of clay.

\subsection{PLT Results}

3.4.1. Relationship between Load and Settlement. Figure 9 shows the typical curve of PLT results of soil. The curve demonstrates the relationship between applied load $P$ and settlement $s$ (namely, $P$-s curve). The $P$-s curve of PLT can be divided into three phases: linear deformation stage, shear deformation stage, and failure stage. In most cases, the point $\left(P_{u}\right)$ corresponding to the deformation stage is the maximum bearing capacity of the foundation. Generally, there is a significant increase of the slope on the curve segment corresponding to $P_{u}$. In this paper, the foundation bearing capacity represents by the load corresponding to the point before the slope of the $P$-s curve increases significantly. 


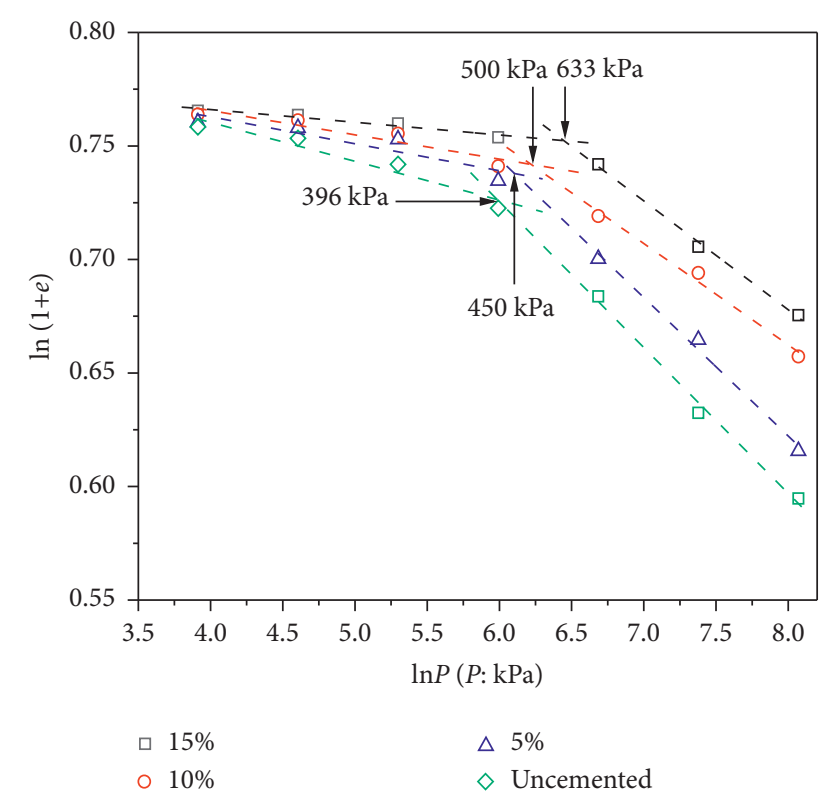

FIGURE 8: Bilogarithmic compression curves of calcareous sand with and without cement.

TABLe 7: Compression parameters of different silts [19, 38].

\begin{tabular}{lcccc}
\hline Soil type & $E_{s}(\mathrm{MPa})$ & $C_{c}$ & $C_{s}$ & $C_{c} / C_{s}$ \\
\hline Uncemented & 10.53 & 0.190 & 0.012 & 15.83 \\
$5 \%$ & 11.75 & 0.177 & 0.013 & 13.61 \\
$10 \%$ & 19.07 & 0.128 & 0.02 & 6.40 \\
$15 \%$ & 32.62 & 0.098 & 0.023 & 4.26 \\
Australia calcareous sand & - & $0.18 \sim 0.24$ & 0.065 & 12.62 \\
Sandbar soil & 19.03 & 0.106 & 0.004 & 26.50 \\
Lagoon soil & 13.57 & 0.176 & 0.007 & 25.14 \\
London clay & 7.20 & 0.161 & 0.062 & 2.58 \\
Weald clay & - & 0.093 & 0.035 & 2.66 \\
Kaolin clay & - & 0.260 & 0.050 & 5.20 \\
\hline
\end{tabular}

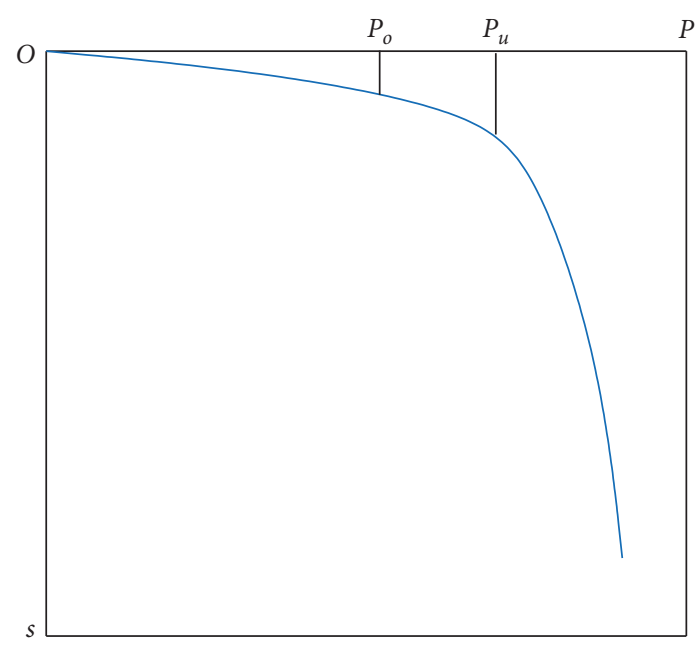

Figure 9: A typical curve of PLT result.

3.4.2. Portland Cement Content. The bearing capacity of cemented calcareous sand is investigated by comparing experiment groups 1 and 3 to 5 , and the $P$-s curves are presented in Figure 10. The relationship between load and settlement of cemented calcareous sand with cement contents of $10 \%$ and $15 \%$ is similar to that shown in Figure 9. The $P$-s curve of the samples with $5 \%$ cement content shows a linear relationship that no obvious failure yield point occurred. When the load is up to $400 \mathrm{kPa}$, the settlement of PLTs with $0 \%, 5 \%, 10 \%$, and $15 \%$ cement content is $13.2 \mathrm{~mm}$, $8.1 \mathrm{~mm}, 2.4 \mathrm{~mm}$, and $1.4 \mathrm{~mm}$, respectively.

The cement content of $5 \%$ is slightly insufficient to improve the bearing capacity of calcareous sand. For the calcareous sand with $15 \%$ cement content, the deformation develops steadily under loading. The sample fails when the load reaches $550 \mathrm{kPa}$, and the deformation is $3.64 \mathrm{~mm}$. Therefore, only when the cement content of calcareous sand is greater than or equal to $15 \%$, the bearing capacity could be improved effectively.

Wang conducted in situ PLTs in Lagoon and Sandbar. Due to the geological history, the calcareous sand in Lagoon and Sandbar is slightly cemented. Figure 11 shows the compassion of the PLTs of natural cemented calcareous sand and cement-stabilized calcareous sand. The cementation degree of the natural cemented calcareous sand is not evaluated because of its complex formation.

It can be found that under the same load, the settlement of the artificial cemented calcareous sand is smaller than that of the naturally cemented calcareous sand. Because the particle bond force formed by biological factors of naturally cemented calcareous is easy to be broken under loading. From the MICP method simulating the cementation of natural calcareous sand, it has been found that the strength of samples cemented by MICP is weaker than that of the samples cemented by Portland. It means that Portland cement could significantly improve the bearing capacity of calcareous sand.

3.4.3. Influence of the Thickness of Cemented Layer. Figure 12 shows the test results of PLT tests with different cemented thickness layers. A thicker layer can provide a higher bearing capacity than the thinner one. The thinner cement stabilized layer will be punctured by increasing load and results in a rapid settlement. When the cementing layer is thick, it can diffuse the upper load and then be resistant to splitting damage to improve the bearing capacity of the foundation. Therefore, the impact of the cemented layer should be taken into consideration in the design of foundations, that is, a thick enough cement stabilized layer of foundation can avoid the occurrence of destructive settlement under high load.

3.4.4. Water Content. The model test mainly uses dry calcareous sand with a water content of $7 \%$ to $9 \%$. Coral reefs experience high and low tide every day so that the calcareous sand foundation on the island reef will be submerged below the seawater. It is necessary to consider this issue when using cement to stabilize the calcareous sand foundation. Therefore, the bearing capacity and deformation characteristics of calcareous sand under dry and saturated conditions are studied as shown in Figure 13. The deformation of dry 


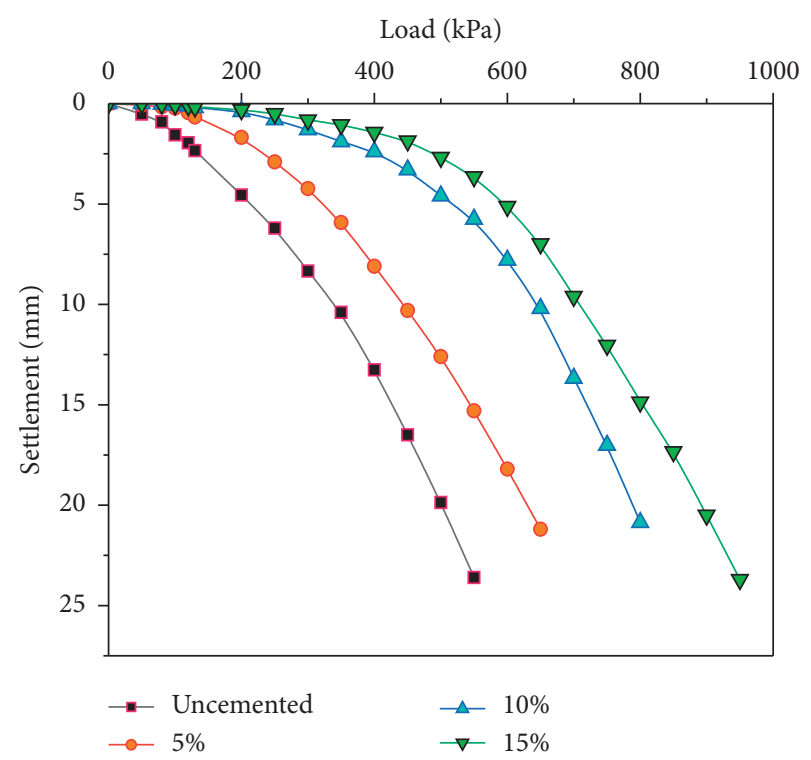

FIgURE 10: Bearing capacity of calcareous sand with different cement content.

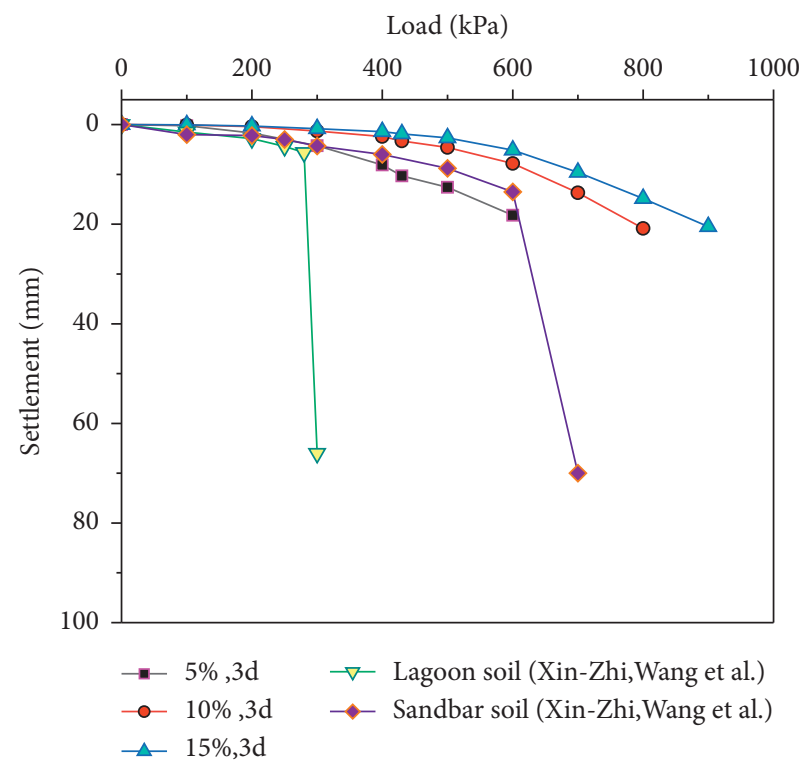

FIgURE 11: Comparison of bearing capacity of calcareous sand [4].

uncemented calcareous sands is smaller than that of the cemented calcareous sands and has a stable development with the increase of load. By contrast, the bearing capacity of the saturated uncemented calcareous sand is relatively lower.

The deformation of saturated cemented calcareous sand is larger than that of dry cemented sand, but the difference is insignificant. Before the sand is cemented, the final deformation of the saturated calcareous sand is $29.8 \mathrm{~mm}$, and the bearing capacity is only $80 \%$ of that of the dry foundation. However, after the cement stabilization of calcareous sand, the final deformation is $24.5 \mathrm{~mm}$. The difference of the deformation between saturated and dry sand becomes smaller after the cement stabilization, and when the load is up to $600 \mathrm{kPa}$, the difference of the deformation is only

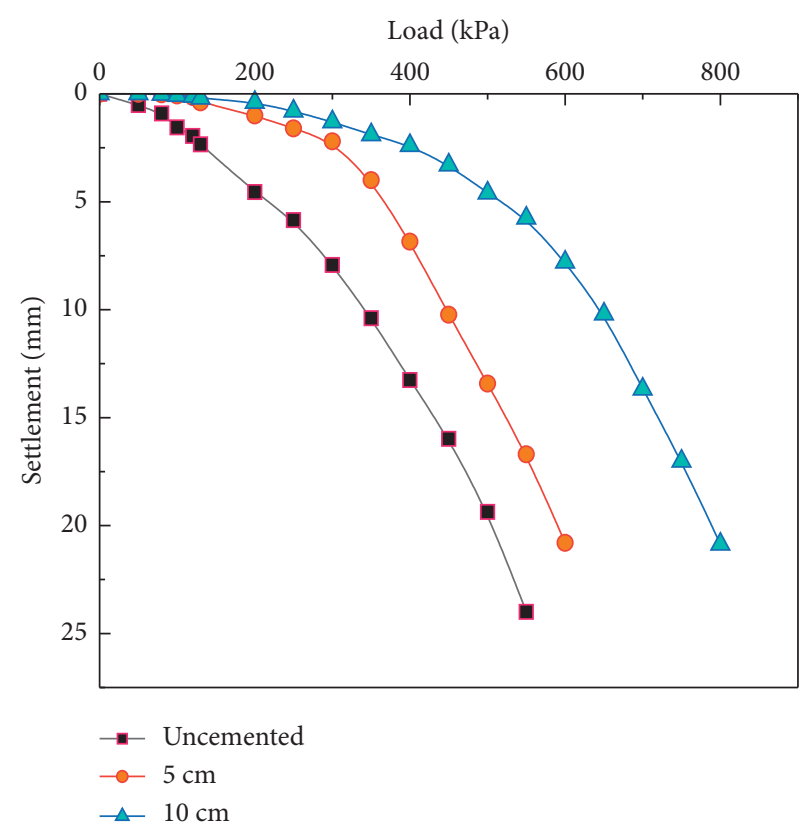

FIGURE 12: Bearing capacity of cemented calcareous sand with the different layer thickness.

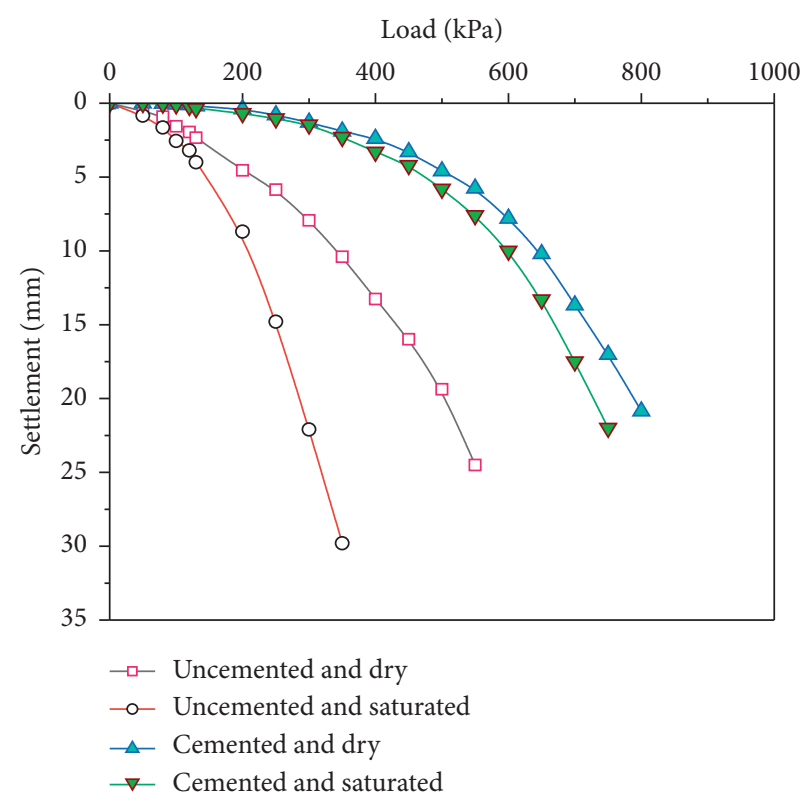

FIgURe 13: Results of PLTs of dry and saturated foundation.

$2.2 \mathrm{~mm}$. It can be seen that the bearing capacity of the saturated calcareous sand foundation is significantly improved by cement solidification. Similarly, the bearing capacity of calcareous sand foundation in seawater can be effectively improved by cementation.

3.4.5. Earth Pressure Distribution. The depth of load transmission that is a major concern for foundation designers should be considered in the calculation of the calcareous sand foundation. This is due to the change of local soil pressure transfer rule after the foundation is cement- 
stabilized and the specific mechanical behavior of calcareous sand.

Figure 14 shows the distribution of earth pressure at different vertical depths and different horizontal widths from the center when the load is $200 \mathrm{kPa}$. Under loading, the earth pressures decrease rapidly with increasing depth as presented in Figure 14(a). At a depth of $40 \mathrm{~cm}$, the earth pressure decayed significantly, more than $50 \%$. As shown in Figure 14(b), at a horizontal level $40 \mathrm{~cm}$ deep in the test model bucket, the earth pressure decreases significantly with increasing distance from the center. When the distance from the center is $18 \mathrm{~cm}$, the earth pressure decreases up to $70 \%$.

The results prove that the effective distance of load transmission on the bearing capacity of the calcareous sand foundation is mainly concentrated in the range of $1 \sim 2$ times of bearing plate width in the horizontal direction and 2 3 times of bearing plate width in the vertical direction. When the upper layer of the calcareous sand is reinforced with cement, the transfer law of soil pressure in the vertical direction does not change much, but the earth pressure in the same position decreases somewhat. However, at a horizontal level of $40 \mathrm{~cm}$ deep, the earth pressure, which is at $18 \mathrm{~cm}$ and $36 \mathrm{~cm}$ away from the central load, increased by different ranges: a larger increase at $18 \mathrm{~cm}$ and a smaller increase at $36 \mathrm{~cm}$.

3.4.6. Deformation Modulus of Different Cement Stabilized Calcareous Sand. The deformation characteristics of calcareous sand are evaluated by deformation modulus, which is calculated according to the equation (2) for deformation modulus of shallow layer plate load test:

$$
E_{0}=I_{0}\left(1-\mu^{2}\right) \frac{P_{p l} d}{s}
$$

where $E_{0}(\mathrm{MPa})$ is deformation modulus; $I_{0}$ is settlement influence modulus with a value of 0.886 when the plate is rigid square; $\mu$ is Poisson's ratio of calcareous sand, and in this paper, $\mu$ is $0.3 ; d(\mathrm{~m})$ is the width of bearing plate; $P_{\mathrm{pl}}$ $(\mathrm{kPa})$ is the proportional limit of load; and $s(\mathrm{~mm})$ is the settlement of loading plate corresponding to load $P_{\mathrm{pl}}$.

Figure 15 shows the deformation modulus of the cemented calcareous sand with different cement contents. When the cement content increases from $5 \%$ to $10 \%$, the deformation modulus increases from $0.68 \mathrm{MPa}$ to $1.01 \mathrm{MPa}$ at the cemented thickness of $10 \mathrm{~cm}$. When the cement content increases from $10 \%$ to $15 \%$, deformation modulus increases from 1.01 MPa to $1.14 \mathrm{MPa}$. From the perspective of foundation reinforcement engineering, the strength of calcareous sand could be effectively improved with $10 \%$ and $15 \%$ cement content, which could improve the deformation modulus and reduce the ground subsidence. In addition, under the premise of sufficient cement content, the thickness of cementation layer is also one of the necessary conditions for improving the foundation bearing capacity. For the two groups of specimens with the same cement content, the deformation modulus of the cemented layer with $5 \mathrm{~cm}$ is $66.3 \%$ of $10 \mathrm{~cm}$ thick ones, and the deformation modulus of the two groups is quite different. In this paper, the total depth of the foundation is $75 \sim 80 \mathrm{~cm}$, and a cementation layer with a thickness of $1 / 8$ of the foundation can effectively improve the bearing capacity of the foundation. In reef engineering, the thickness of the sand layer is usually $5 \sim 10 \mathrm{~m}$, so a cementation layer with a thickness of $0.65 \sim 1.25 \mathrm{~m}$ should be designed to improve the bearing capacity of the foundation at least.

\section{Calculation and Comparison of Ultimate Bearing Capacity}

4.1. Ultimate Bearing Capacity. The vertical bearing capacity of a shallow foundation resting on a homogeneous soil profile is most often determined from the following equation [39]:

$$
P_{u}=c N_{c}+q N_{q}+\frac{1}{2} \gamma b N_{\gamma},
$$

where $p_{u}$ is bearing capacity, $\mathrm{kPa} ; c$ is the apparent cohesion of soil, $\mathrm{kPa} ; b$ is the width of load plate, $\mathrm{m}$; and $N_{c}, N_{q}$, and $N_{\gamma}$ are dimensionless bearing capacity factors, which are only related to the internal friction angle.

Calcareous sand foundations with different surface cementing thicknesses are double-layered composite foundations. The vertical bearing capacity of composite foundations is different from that of ordinary foundations. According to the Chinese standard (JGJ79-2002), the bearing capacity of composite foundations can be estimated as follows:

$$
P_{u}=m\left(c N_{c}+q N_{q}+\frac{1}{2} \gamma b N_{\gamma}\right)+(1-m) P_{\text {kum }},
$$

where $m$ is a coordination coefficient based on local experience and $P_{\text {kum }}$ is the bearing capacity of the foundation without cement treatment.

For a square foundation, the following semiempirical formula was proposed to calculate the ultimate bearing capacity of the foundation. Table 8 compares the test results of UCS, ultimate bearing capacity measured by PLT and calculated by the following equation:

$$
P_{u}=m\left(1.2 c N_{c}+q N_{q}+0.4 \gamma b N_{\gamma}\right)+(1-m) P_{\text {kum }} .
$$

It can be seen from Table 8 that the calculated results are greater than the test results, especially when the calcareous sand foundation is cemented. With the increase of cement content, the gap between the calculated value and the test value is getting larger; the formula of ultimate bearing capacity cannot accurately calculate the ultimate bearing capacity of the calcareous sand foundation. The ultimate bearing capacity calculation method (equation (5)) assumes that the foundation soil is an incompressible rigid plastic body, so it is only applicable to the case that the foundation is a general-shear failure mode. When the foundation is cemented, the mechanical property and failure mode have changed. The failure mode changed from general-shear failure mode (vide Figure 16(a)) to the punching failure mode (vide Figure 16(b)). If the ultimate bearing capacity calculation method is still used in this condition, the 


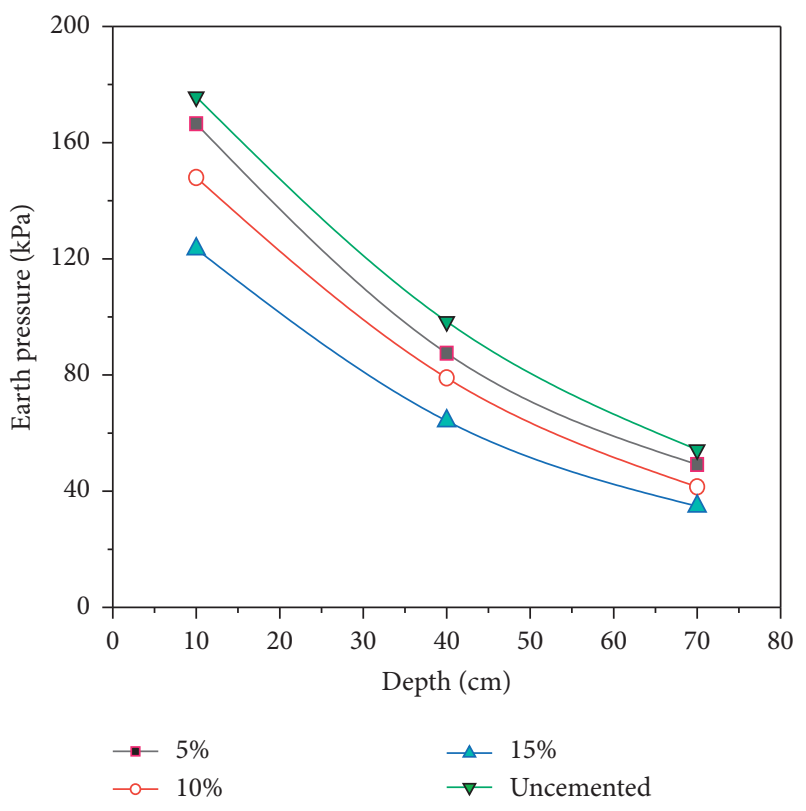

(a)

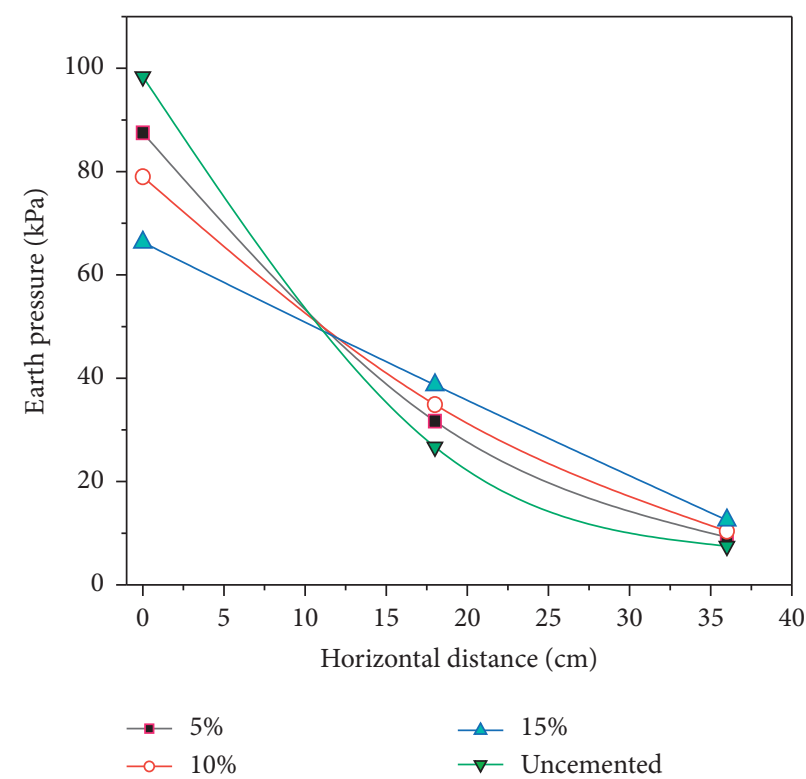

(b)

FIGURE 14: Earth pressure distribution of calcareous sand in different positions $(P=200 \mathrm{kPa})$ : (a) depth (cm) and (b) horizontal distance $(\mathrm{cm})$.

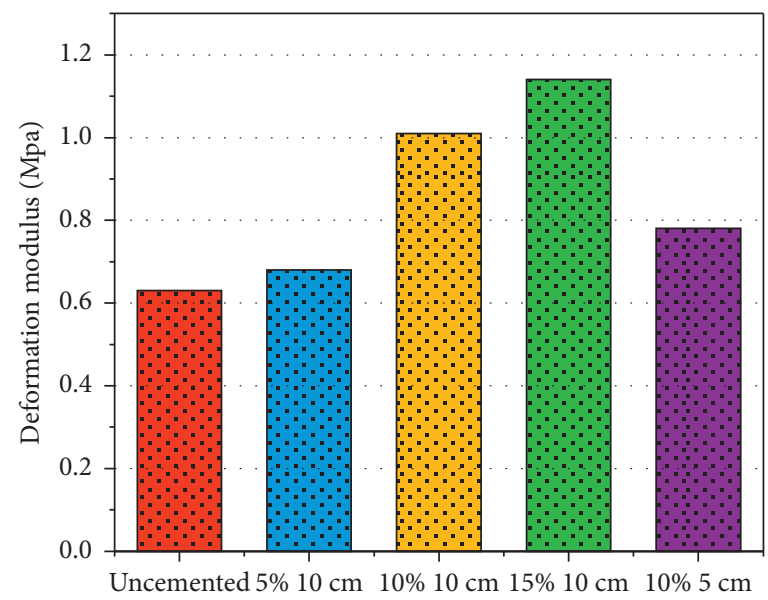

FIGURE 15: Deformation modulus of different cement stabilized calcareous sand foundations.

TABLE 8: Comparison of ultimate bearing capacity.

\begin{tabular}{lccccc}
\hline Soil type & Apparent cohesion, $c(\mathrm{kPa})$ & Internal friction angle, $\varphi\left(^{\circ}\right)$ & $P_{\mathrm{u}}(\mathrm{kPa})$ & $\mathrm{UCS}(\mathrm{kPa})$ & Test results $(\mathrm{kPa})$ \\
\hline Uncemented & 0 & 36.50 & 184.04 & - & 150 \\
$5 \%$ & 2.51 & 34.07 & 341.24 & 363.73 & 300 \\
$10 \%$ & 18.17 & 33.20 & 753.37 & 562.70 & 500 \\
$15 \%$ & 30.25 & 33.87 & $1,157.02$ & 667.23 & 550 \\
\hline
\end{tabular}

calculation result is larger. In contrast, the value of UCS was chosen to represent the bearing capacity of the foundation.

4.2. Settlement. As one of the most mainstream methods of foundation settlement analysis, the layered summation method has been widely used in the foundation settlement analysis. The layered summation method will calculate the settlement of different layers separately and then summarize all for getting the total settlement $[40,41]$. Based on the compression test data, the settlement of foundation can be obtained by the following equation:

$$
s=\sum s_{i}=\frac{e_{1 i}-e_{2 i}}{1+e_{1 i}} h_{i},
$$




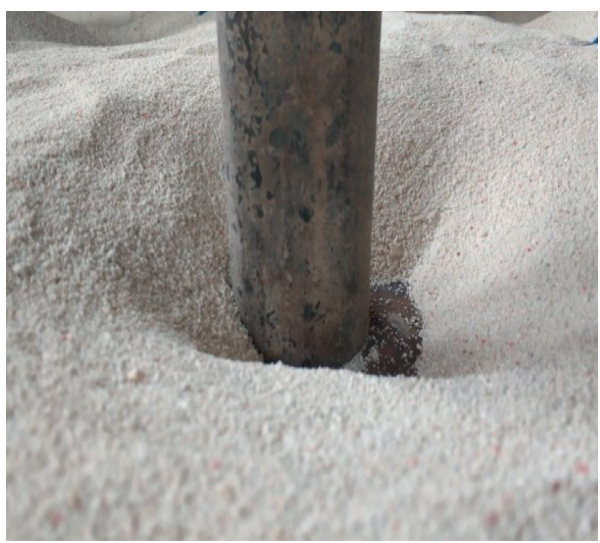

(a)

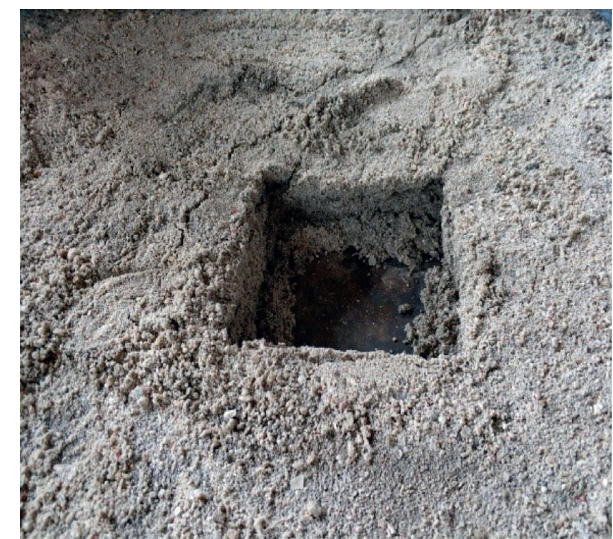

(b)

FIGURE 16: Different failure modes of calcareous sand foundation.

where $s$ is the total settlement, $\mathrm{cm} ; e_{1 i}$ and $e_{2 i}$, respectively, refer to the pore ratio before and after the load is applied to the soil layer; and $h_{i}$ is the thickness of the layer, $\mathrm{cm}$.

Due to the shallow depth of the model test box, the gravity stress of calcareous sand is very small compared to the additional stress caused by load, so that the gravity stress can be neglected in the calculation. Comparison of settlements by calculation and experiments is presented in Figure 17. For uncemented calcareous sand, the calculated settlement is slightly smaller than that of the test result, while for cemented calcareous sand, the settlements by calculation are greater than those by experiments. It is induced by the change of the stress distribution caused by the cementation of the top layer of the foundation. The cementation of the upper layer of calcareous sand forms a whole sand block; the load on the top is no longer propagated along the vertical direction alone but diffused through the reinforced calcareous sand layer to the outer side away from the axial load. The pressure on the central position is reduced, and hence, the additional stress no longer just transmits along vertical downward but also spreads towards surround. It is proved in Figure 15 that in the foundation with a cemented surface, the soil pressure monitored in the vertical direction is less than that in the uncemented foundation under the same load, but the soil pressure at the horizontal position of $18 \mathrm{~cm}$ and $36 \mathrm{~cm}$ in the middle of the test model bucket is larger than that in the uncemented foundation; it indicates that the cemented surface acts as a bearing layer for load dispersion transfer, thus reducing the soil pressure under load plate. As a result, the layered summation method cannot predict the soil pressure drop caused by this condition, which leads to the calculated settlement being larger than the test results.

In terms of error, the layered summation method is suitable for calculating the settlement of uncemented calcareous sand, and the calculation results can be used to predict the settlement of the foundation. However, for the cemented calcareous sand, the calculation value is $24 \%$ to $27 \%$ lower than the actual settlement, and the layered summation method is not suitable for predicting the settlement of the cemented calcareous sand foundation.

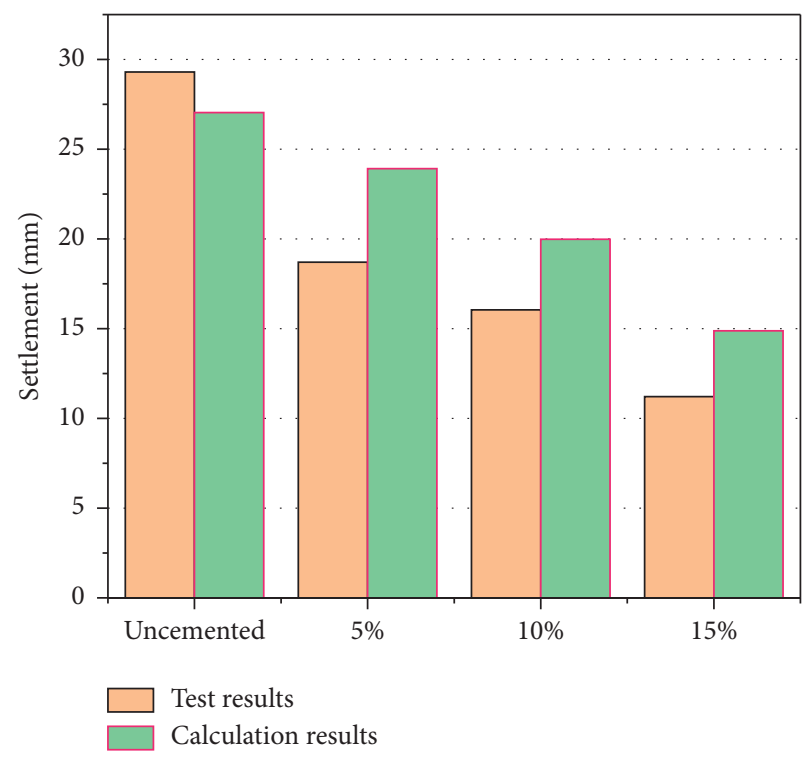

Figure 17: Comparison of settlement in calculation results and test results $(P=400 \mathrm{kPa})$.

\section{Conclusions}

A series of laboratory experiments were conducted on calcareous sand from the South China Sea to investigate the engineering characteristics of cement stabilized calcareous sand. The main conclusions are as follows:

(1) The UCS of calcareous sand with cement contents of $5 \%, 10 \%$, and $15 \%$ at different curing times was obtained. The UCS of the cemented calcareous sand is higher than that of cemented Guangzhou soft soil but lower than that of quartz sand.

(2) The consolidation yield stress, $C_{c}, C_{s}$, and $E_{s}$, of cement calcareous sand were obtained by consolidation test. The deformation of calcareous sand during compression is mainly plastic, and elastic deformation accounts for $6.1 \% \sim 32.3 \%$ of the total deformation. The elastic deformation increases with increasing cement content. 
(3) The results of the laboratory direct shear test indicate that the apparent cohesion of calcareous sand increases, while internal friction angle decreases with increasing cement content. The decrease in internal friction angle is induced by particle cementation. After cementation, the pores and pockmarks of calcareous sand particles are filled and covered by the cement gel. The surfaces become flat and smooth, and the edges and corners become rounded. As a result, sand particles easily slide over each other, and the internal friction angles of cemented calcareous sand decrease.

(4) The PLT results indicate that the bearing capacity of calcareous sand can be significantly improved by using the cement-stabilized method, especially for the saturated state. The reinforced calcareous sand layer shares part of the load, reducing the pressure on the central position, and hence, the additional stress no longer just transmits along vertical downward. The bearing capacity could be effectively improved by a cement content equal to or more than $15 \%$ and a cement thickness of $1 / 8$ of the foundation. 5 . The calculated results of the ultimate bearing capacity method are greater than the test results. With the increase of cement content, the gap of the bearing capacity by calculation and experiments becomes larger. It is suggested to use the UCS to calculate the bearing capacity of the cemented calcareous sand. On the other hand, for cement-stabilized calcareous sand foundation, the calculated value of the settlement is $24 \%$ to $27 \%$ lower than the actual settlement.

\section{Data Availability}

The data used to support the findings of this study are included within the article.

\section{Ethical Approval}

Ethical review and approval were waived for this study because the institutions of the authors who participated in data collection do not require IRB review and approval.

\section{Conflicts of Interest}

The authors declare that they have no conflicts of interest.

\section{Authors' Contributions}

C. Y. and L. H. B. conceptualized the study; C. Y. contributed to the methodology; C. Y. and W. F. J. had done the validation; L. H. B. contributed to the resource collection; C. Y. and J. D. P. had done the data curation; C. Y. contributed to the preparation of the original draft; W. F. J. and J. D. P. contributed to review and editing the manuscript; and L. H. B. contributed to the project administration. All the authors have read and agreed to the final version of the manuscript.

\section{Acknowledgments}

This work was financially supported by the Natural Science Foundation of China (grant number: 51169005) and the Natural Science Foundation of Guangxi, China (grant number: 2018GXNSFDA281038).

\section{References}

[1] E. W. Schwiderski, "On charting global ocean tides," Reviews of Geophysics, vol. 18, no. 1, pp. 243-268, 1980.

[2] A. Ha and F. M. Shaqour, "Geotechnical implications of subsurface water rise in Kuwait," Engineering Geology, vol. 31, pp. 59-69, 1991.

[3] M. R. Coop, K. K. Sorensen, T. Bodas Freitas, and G. Georgoutsos, "Particle breakage during shearing of a carbonate sand," Géotechnique, vol. 54, no. 3, pp. 157-163, 2004.

[4] X.-Z. Wang, X. Wang, Z.-C. Jin, C.-Q. Zhu, R. Wang, and Q.-s. Meng, "Investigation of engineering characteristics of calcareous soils from fringing reef," Ocean Engineering, vol. 134, pp. 77-86, 2017.

[5] J. L. Alba and J. M. Audibert, "Pile design in calcareous and carbonaceous granular materials, an historic overview," in Proceedings of the Second International Conference on Engineering for Calcareous Sediments, pp. 29-44, Manama, Bahrain, February 1999.

[6] H. D. C. P. Salehzadeh and C. M. Merrifield, "Medium dense non-cemented carbonate sand under reversed cyclic loading," International Journal of Civil Engineering, vol. 4, pp. 54-63, 2006.

[7] W. Jiang, K. Yu, Y. Song et al., "Coral geochemical record of submarine groundwater discharge back to 1870 in the northern South China Sea," Palaeogeography, Palaeoclimatology, Palaeoecology, vol. 507, pp. 30-38, 2018.

[8] M. C. B. C. sediments, "An engineering enigma," in Proceedings of the Internatioan Conference on Calcareous Sediments, pp. 777-784, Perth, Australia, March 1988.

[9] Y. Wang, L. Zhou, Y. Wu, and Q. Yang, "New simple correlation formula for the drag coefficient of calcareous sand particles of highly irregular shape," Powder Technology, vol. 326, pp. 379-392, 2018.

[10] Y. Wu, N. Li, X. Wang et al., "Experimental investigation on mechanical behavior and particle crushing of calcareous sand retrieved from South China Sea," Engineering Geology, vol. 280, Article ID 105932, 2021.

[11] Y. Wu, J. Cui, J. Huang, W. Zhang, N. Yoshimoto, and L. Wen, "Correlation of critical state strength properties with particle shape and surface fractal dimension of clinker ash," International Journal of Geomechanics, vol. 21, no. 6, Article ID 4021071, 2021.

[12] E. Loth, "Drag of non-spherical solid particles of regular and irregular shape," Powder Technology, vol. 182, no. 3, pp. 342-353, 2008.

[13] G. Spagnoli, P. Doherty, G. Murphy, and A. Attari, "Estimation of the compression and tension loads for a novel mixed-in-place offshore pile for oil and gas platforms in silica and calcareous sands," Journal of Petroleum Science and Engineering, vol. 136, pp. 1-11, 2015.

[14] Y. Tian, M. J. Cassidy, and C. Gaudin, "Advancing pipe-soil interaction models in calcareous sand," Applied Ocean Research, vol. 32, no. 3, pp. 284-297, 2010.

[15] K. F. Lambrakos, "Marine pipeline soil friction coefficients from in-situ testing," Ocean Engineering, vol. 12, no. 2, pp. 131-150, 1985. 
[16] X. Wang, "Experimental investigation on cementation of calcareous sand and its basic mechanical characteristics," Journal of Experimental Mechanics, vol. 24, pp. 133-143, 2009.

[17] M. Hyodo, A. F. L. Hyde, and N. Aramaki, "Liquefaction of crushable soils," Géotechnique, vol. 48, pp. 527-543, 1998.

[18] F. M. Shaqour, "Cone penetration resistance of calcareous sand," Bulletin of Engineering Geology and the Environment, vol. 66, no. 1, pp. 59-70, 2007.

[19] X.-Z. Wang, Y.-Y. Jiao, R. Wang, M.-J. Hu, Q.-S. Meng, and F.-Y. Tan, "Engineering characteristics of the calcareous sand in Nansha islands, South China sea," Engineering Geology, vol. 120, no. 1-4, pp. 40-47, 2011.

[20] X. Wang, Y. Weng, H. Wei, Q. Meng, and M. Hu, "Particle obstruction and crushing of dredged calcareous soil in the Nansha Islands, South China Sea," Engineering Geology, vol. 261, Article ID 105274, 2019.

[21] X. Wang, H. Ding, Q. Meng, H. Wei, and Y. Wu, "Engineering characteristics of coral reef and site assessment of hydraulic reclamation in the South China Sea," Construction and Building Materials, vol. 300, 2021.

[22] A. Ata, T. N. Salem, and R. Hassan, "Geotechnical characterization of the calcareous sand in northern coast of Egypt," Ain Shams Engineering Journal, vol. 9, no. 4, pp. 3381-3390, 2018.

[23] S. Li, X. Huang, S. Wu, J. Tian, and W. Zhang, "Bearing capacity of stabilized soil with expansive component confined by polyvinyl chloride pipe," Construction and Building $\mathrm{Ma}$ terials, vol. 175, pp. 307-320, 2018.

[24] E. Çokça, "Use of class C fly ashes for the stabilization of an expansive soil," Journal of Geotechnical and Geoenvironmental Engineering, vol. 127, pp. 568-573, 2001.

[25] T. B. Edil, A. A. Hector, and C. H. Benson, "Stabilizing soft fine-grained soils with fly ash," Journal of Materials in Civil Engineering, vol. 18, pp. 283-294, 2006.

[26] K. Q. Tran, T. Satomi, and H. Takahashi, "Improvement of mechanical behavior of cemented soil reinforced with waste cornsilk fibers," Construction and Building Materials, vol. 178, pp. 204-210, 2018.

[27] M. Bekhiti, H. Trouzine, and M. Rabehi, "Influence of waste tire rubber fibers on swelling behavior, unconfined compressive strength and ductility of cement stabilized bentonite clay soil," Construction and Building Materials, vol. 208, pp. 304-313, 2019.

[28] Q. Zhang, Q. Shi, G. Chen et al., "Status monitoring and health assessment of Luhuitou fringing reef of Sanya, Hainan, China," Chinese Science Bulletin, vol. 51, no. S2, pp. 81-88, 2006.

[29] P. O. Van Impe, W. F. Van Impe, A. Manzotti, P. Mengé, M. Van den Broeck, and K. Vinck, "Compaction control and related stress-strain behaviour of off-shore land reclamations with calcareous sands," Soils and Foundations, vol. 55, no. 6, pp. 1474-1486, 2015.

[30] F. Xiong, H. Xing, and H. Li, "Experimental study on the effects of multiple corrosive ion coexistence on soil-cement characteristics," Soils and Foundations, vol. 59, no. 2, pp. 398-406, 2019.

[31] R. S. Ladd, "Preparing test specimens using undercompaction," Geotechnical. Testing Journal ASTM, vol. 1, pp. 16-23, 1978.

[32] S. Liang, J. Chen, M. Guo, D. Feng, L. Liu, and T. Qi, "Utilization of pretreated municipal solid waste incineration fly ash for cement-stabilized soil," Waste Management, vol. 105, pp. 425-432, 2020.
[33] G. Vinoth, S.-W. Moon, J. Moon, and T. Ku, "Early strength development in cement-treated sand using low-carbon rapidhardening cements," Soils and Foundations, vol. 58, no. 5, pp. 1200-1211, 2018.

[34] H. G. Brandes, "Simple shear behavior of calcareous and quartz sands," Geotechnical \& Geological Engineering, vol. 29, no. 1, pp. 113-126, 2011.

[35] B. Da, H. Yu, H. Ma, Y. Tan, R. Mi, and X. Dou, "Experimental investigation of whole stress-strain curves of coral concrete," Construction and Building Materials, vol. 122 , pp. 81-89, 2016.

[36] A. Casagrande, "The determination of pre-consolidation load and its practical significance," in Proceedings of the 1st International Conference on Soil Mechanics, Harvard, MA, USA, June 1936.

[37] R. Butterfield, "Natural compression law for soils (an advance on e-log p)," Géotechnique, vol. 29, pp. 469-480, 2015.

[38] J. K. Mitchell and K. Soga, Fundamentals of Soil Behavior, John Wiley \& Sons, New York, NY, USA, 2005.

[39] K. Terzaghi, Theoretical Soil Mechanics, INC, New York, NY, USA, 1943.

[40] G. A. Lorenzo and D. T. Bergado, "New consolidation equation for soil-cement pile improved ground," Canadian Geotechnical Journal, vol. 40, no. 2, pp. 265-275, 2003.

[41] R. F. Craig, Soil Mechanics, Springer, Berlin, Germany, 2013. 